\title{
The Einstein chronicles
}

\section{Two volumes of correspondence put Einstein's work in a historical context.}

\section{The Collected Papers of Albert Einstein, Volume 9. The Berlin Years: Correspondence, January 1919-April 1920 \\ edited by Diana Kormos Buchwald, Robert Schulmann, József Illy, Daniel J. Kennefick \& Tilman Sauer Princeton University Press: 2004. 780 pp. $\$ 110, £ 72$}

\section{The Born-Einstein Letters} 1916-1955: Friendship, Politics and Physics in Uncertain Times by Albert Einstein \& Max Born Macmillan Science: 2005. 256 pp. $£ 19.99, \$ 26.95$

\section{Gerald Holton}

On 22 September 1919, Albert Einstein, then aged 40 , received at his Berlin home a brief telegram that signalled that his life would shortly change, suddenly and forever. The telegram contained the news that Arthur Eddington had shown during a solar eclipse that starlight is deflected by the Sun's gravity - an effect predicted by Einstein's general theory of relativity. The scientific details, when published that November, made Einstein almost overnight the icon of charismatic scientific genius. The very stars had announced, to a public still in mourning after the barbaric First World War, that old conceptions were being overturned. Einstein's vast correspondence during the months that followed reveal the reactions, ranging from adoration to vicious attacks.

This tumultuous period is recorded in volume 9 of The Collected Papers of Albert Einstein. The 399 letters and other documents included, most of them previously unpublished, offer us an intimate view of the remarkable multidimensionality of Einstein's life. Much of the correspondence is of course about the scientific findings and controversies of the time, chiefly on the lightbending and red-shift tests of his general theory of relativity, the attempt to find common ground between quantum mechanics and relativity, and the programme to unify electromagnetism and gravitation.

Even an incomplete list of Einstein's scientific correspondents in this period will draw historians of science and other scholars to this volume: Paul Ehrenfest, Theodor Kaluza, Felix Klein, David Hilbert, Gustav Mie, Adriaan Fokker, Max von Laue, Hendrik Lorentz, Jean Perrin, Eddington, Willem de Sitter, Hedwig Kohn — and not forgetting the English physicist Robert W. Lawson, who persuaded Einstein to write an article for Nature in 1921 outlining his theory of relativity.

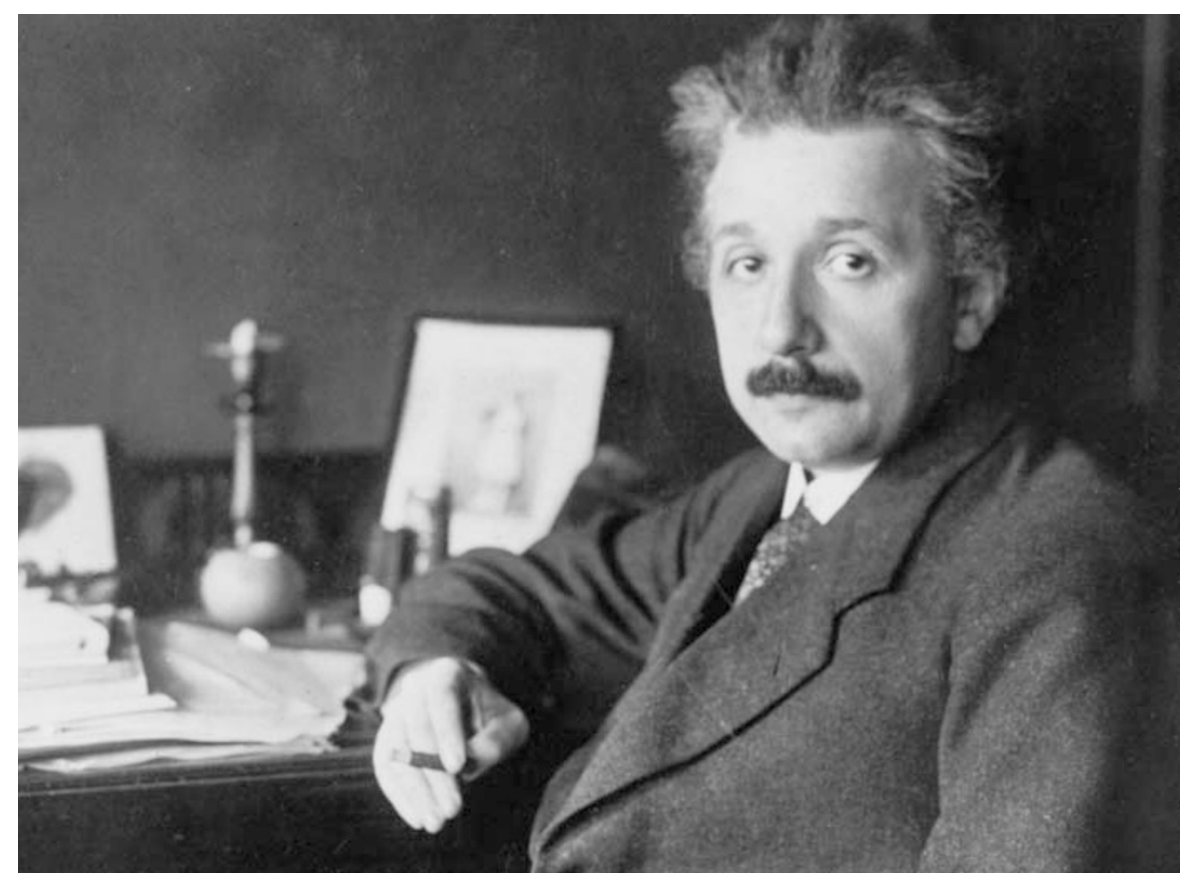

Man of letters: Einstein's correspondence provides a wealth of personal and scientific information.

Other letters deal with epistemological questions (such as exchanges with Moritz Schlick and Hans Vaihinger); with administrative, political and social problems, including Einstein's intensifying interest in a Jewish identity and in a form of Zionism. From more personal letters, we learn about Einstein's own precarious health in those days, and his deep grief as his mother is dying of cancer. Throughout there is evidence of his often difficult relations with his wife Mileva, who, soon after the family arrived in Berlin in 1914, returned to Switzerland with their two sons, for whom Einstein's letters show his great attachment. Also included are the decree of divorce from Mileva (dated 14 February 1919) and the certificate of his marriage to his cousin Elsa Löwenthal (2 June 1919, both registering their religion on the document as "Dissident").

There is as much as a page of editorial explanation and commentary on every name, place and allusion recorded in the corresponding letter - an astonishing combination of scholarship and detective work by the editorial team, now led by Diana Kormos Buchwald and continuing the tradition established by John Stachel, who edited earlier volumes. These annotations establish not only the relationship between different parts of the whole correspondence (the first volume was published in 1987), but also tell us much about the scientific and social milieu of the day, something only hinted at in the letters themselves.
For example, in a letter of November 1919 to Einstein, Lawson mentions in passing that he understands that "the conditions of life in Berlin are nearly unbearable". The editorial note explains: "The Allied blockade of Germany, which was extended past the end of the war to pressure Germany to accede to Allied demands, together with economic disruption from the war, caused a famine in central Europe in the aftermath of the war." There is then a discussion about the spread of disease.

Similarly, to clarify an obscure sentence in a letter by Fokker (dated 18 November 1919), the editorial note explains that, in testifying that month before the German official committee exploring the responsibilities of the military during the war, General Hindenburg "used the occasion to launch the 'stab-in-the-back' legend which blamed civilian groups such as the communists, Jews, and women for Germany's defeat in the war". The 'stab-in-the-back' legend "served as a catalyst for those embittered by Germany's defeat, fueling the consolidation of rightist and militarist attitudes in Weimar Germany".

All this carefully researched editorial commentary makes it easy to grasp the context and conditions underlying the correspondence. Einstein usually seems somehow lifted above it all, being saved in those dark days largely by what Max Planck pointedly identified as "die freudige Sicherheit" — the joyful certainty.

A 24-page introduction serves as a guide 
to the main events and ideas in the correspondence; without it, it would be difficult to keep in mind the main themes when reading the chronological series of letters. There is also an explanation of the editors' triage of the voluminous correspondence: some letters are known but are inaccessible now, and the editors relegated other, less significant, letters to reference in a calendar at the end of the volume. And although the correspondence is presented only in the original language, mostly German, happily there exists a separately published English translation, provided by Ann and Klaus

Hentschel (Princeton University Press, 2005).

Many of the most intimate letters in volume 9 are exchanges between Einstein and Max Born and his wife Hedwig. Here, Einstein can truly relax and share the good and the sad in his life, his scientific, social, musical and personal thoughts. Max Born, whose Nobel prize for his work in quantum mechanics was delayed until 1954, contributed to a wide spectrum of fields, including relativity, optics, crystal physics, epistemology, the theory of liquids and arms control. Max and Hedwig, who was a delightful companion and correspondent, left Germany for Edinburgh after Max was driven out from Göttingen in 1933. His son, Gustav, tells that his father had taken seriously Einstein's advice to leave immediately, "thus helping to save the family".

The 117 surviving letters between the Borns and Einstein from 1916 to 1955 were published as a book in German in 1969, with an introduction by Werner Heisenberg, at one time Born's assistant. It had a foreword by Bertrand Russell, who succinctly summarized what that book showed in its essence: "In an age of mediocrity and moral pygmies, their lives shine with an intense beauty. Something of this is reflected in their correspondence, and the world is richer for its publication.” For most of the letters, Max Born provided perceptive editorial comments, explaining the circumstances of the time in which the letters were written.

An English translation of the book appeared in 1971, but has been long out of print. The new English-language edition of The Born-Einstein Letters 1916-1955 issued by Nature's publisher Macmillan as part of its new science imprint - is essentially unchanged from the earlier version, but greatly benefits from an extensive preface by Buchwald and the physicist Kip Thorne. To quote from the preface: "The letters themselves constitute one of the most vivid and valuable testimonies to the development of modern science. They also tell us much about the personal hardships that Einstein and Born overcame during two world wars, the vagaries of academic life, the daily grind of administrative work, the steadfastness and frailty of human relationships."

Perhaps the most famous of these letters deal with the fundamental difference between these two good friends, with Born upholding what came to be the Copenhagen interpretation of quantum mechanics, according to which the foundations of physics are laws of statistical nature. Einstein responded in 1926: "Quantum mechanics is certainly imposing. But an inner voice tells me that it is not yet the real thing. The theory says a lot. But it does not really bring us any closer to the secrets of the 'old one'. I, at any rate, am convinced that $\mathrm{He}$ is not playing at dice."

This judgement, Born records, was for him "a hard blow”, separating Einstein from the younger physicists of which Born, though only a few years younger than Einstein, considered himself part. But the friendship survived, not least by the intervention of Wolfgang Pauli, who cleared up a misunderstanding between Born and Einstein. The exchange of letters continued, testifying to their constant interests in developments ranging from atomic physics to cosmic rays, from quantum mechanics to stellar spectra, and of course relativity (the new 'ether drift' experiments, gravitational red shift, gravitational light deflection and gravitational waves).

But we hear also about the pair's intervention in humanitarian causes, the turmoil in politics throughout Europe after the First World War, programmes to help refugee scientists, and the devastating events of the Second World War. The new preface also contains valuable brief accounts of the way that physics, after the death of these two great minds, continued along lines they had pursued, showing in some detail how experimental and theoretical work in the past few decades has confirmed with great precision some of their daring speculations.

In short, these two related volumes act as a kind of microscope through which to view a turbulent period in the twentieth century.

Gerald Holton is Mallinckrodt research professor of physics and research professor of the history of science, Department of Physics, Harvard

University, Cambridge, Massachusetts 02138, USA.

\section{Relativity revisited}

The Meaning of Relativity (5th edn) by Albert Einstein, with an introduction by Brian Greene

Princeton University Press: 2004. 192 pp.

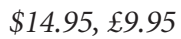

\section{Special Relativity: A First}

Encounter

by Domenico Giulini

Oxford University Press: 2005. 160 pp.

£14.99, \$24.95

Einstein 1905: The Standard

of Greatness

by John S. Rigden

Harvard University Press: 2005. 192 pp.

$\$ 21.95, £ 14.95$

\section{Werner Israel}

What, another three books on Einstein? At the last count on www.amazon.com there were 498 currently in print, and the proliferation of titles such as The Private Albert Einstein, Einstein in Love and Einstein's Daughter should ensure that no corner of his life is left untouched.

As a refreshing change, The Meaning of Relativity, Special Relativity and Einstein 1905 deal exclusively with science. All three are valuable additions to the Einstein canon. The Meaning of Relativity, the master's own presentation based on lectures given at Princeton University in 1921, reappears in a reprinting of the final (1953) edition, which included as an appendix his parting thoughts on his last abortive bid to unify the gravitational and electromagnetic forces. This was in fact a revival, with modifications, of his earliest attempt, begun in 1925 but soon abandoned because, as he admitted in 1927: "As a result of numerous failures, I have come to the conclusion that this road does not lead us closer to the truth." It is curious that none of his later works mentions this early attempt. Not too much should be made of this; Einstein was always sparing with references (this entire book has just one). Yet one cannot help wondering: could it have slipped his mind that he had been down this path before?

Brian Greene's easy-to-read 24-page introduction touches on several developments since Einstein's time. One of these is superstring theory, which carries forward Einstein's quest for unification. Another is the recent discovery that the cosmic expansion is accelerating, with its strong implication that Einstein's self-styled "greatest blunder" — the cosmological constant — was perhaps not such a dumb idea after all.

Giulini's book Special Relativity has a narrower focus, concentrating exclusively on Einstein's special theory of relativity. It is particularly strong on experimental tests and ramifications of the theory, and on the evolution of relativistic ideas, from Galileo and Newton, through the nineteenth-century 